\title{
THE NATURE OF NEAR-SYNONYMIC RELATIONS
}

\author{
Chrysanne DiMarco \\ Department of Computer Science \\ University of Waterloo \\ Watertoo, Ontario, Canada N2J، 3G1 \\ cdimarco(ologos.nwaterloo.ca
}

\section{Introduction}

The words gawp, gaze, and stare all denote a kind of prolonged look: they are nexr-synonyms, or plesionyms [Gruse 1986]. Howeves, as we learn. from their individual entries in the Oxford advanced learner's dictionary (OALD); fourth edition, 1989), to gaze is to look long and steadily; to stare is to do this with the eyes wide open; and gawping has the additional requirement that the act be impolite or stupid. In recent work [1]iMarco, Mirst, and Stede 1993; IDiMarco and IIirst 1993], we address the problem of representing the lexical features that distingutsh gronps of nearsynonyms.

Our lexical foatures for difforentiation are not intended to be any kind of primitives for decompositional semantics: they aro not boing used to represent, whole moanings, but rather to represent differences between meanings. These differences between plesionyms can be shades of denotalion or connotation, or emphases on different components of the meaning.

Our eventual goal is a representation for a lox icon in which semantic and stylistic distinctions can be made between synonyms and plesionyms, both within and across languages, for the pripose of lexical choice in natural language generation and machine translation. 'I'he nature of these dislinctions suggests that they can be viewed as relations between near-synonyms. In this paper, wo undertake a study of the characteristics of nearsynonymic relations as a step towards a knowledge representation for lexical discrimination.

\section{Previous research}

As a first step, which wo described in [I)iMarco, Hirst, and Stede 1993], we carried out al study of dictionary usage notes in order to compile a list of the kinds of dimensions that are used frequently as denotative or comnotative differentiae. Wo produced a preliminary list of 26 denotalional dimensions and 12 connotative dimensions (including a few that wo added from the discussion on lexical aspects by Vinay and barbeluet [1958]). ('This set is not yet complete or definitive, of conrse, but, we have managed to include a fainly compre- hensive selection of the most common differences betwen near-synonyms.) Some of the dimensions are simple binary choices; others are continuous. We show a representative sample in Table 1. Wach line of the table shows a dimension of differentiation followed by example sentences in which two plesionyms vary along that dimension.

\section{Chaffin and Herrmann}

\subsection{Basic theory}

Chalfin and Herenann [1.988] have provided a theoretical approach for accounting for semantic re lations that we will apply to near-synonymic relaw tions. They describe a systematic study of the nature of semantic relations, beginning with a catar logue of the relation properties that an adequate theory of semantic relations should explain, followed by a list of sample relations. These relations (e.g., synomymity, pseudoantonym) are then broken down into relation elements (e.g, symmetrical position, locative inclusion), which are formally defined. Chaffin and Ifermann's study cal. minates with an explanation of how this relationelement approach can be used to account for each of the rolation properties. We will undertake a similar kind of study in proposing a theoretical acconnt of near-synonymic relations. Hlowever, unlike Chadfin and Hermann, who began with readily jecognizable semantic relations and then defined relation elements, we find that in our study of near-synonyms, it is more appropriate to begin with the relation elements, which are more easily identified, and then move on to the construction of the relations, which are more difficult to rlefine.

We will begin by examining four properties that Chaflin and Ilerrmann believe any theory of semantic relations should account for and we will show that these propertios are also relevant to any theory of near-synomymic rolations.'

\footnotetext{
${ }^{1}$ Chafliu and fermann inchule relation discrimination, but as our whole study is of lexical differentiae, all our relation properties have something to do with diserimination. They also incluale relation verification, but a demonstration of this prop erty would involve psychological testing, which we have not yet uncleriaken.
} 


\section{DENOTATIONAT, DIMLNSIONS}

Intentional/accidental:

She $\{$ stared at $\mid$ glimpsed $\}$ him through the window.

\section{Continuous/intermittent:}

Winc $\{$ secped $\mid$ dripped $\}$ from the barrel. Immediate/iterative:

She $\{$ struck $\mid$ beat $\}$ the drum.

Sudden/gradual:

The boy $\{$ shot $\mid$ edged $\}$ across the road.

\section{Degree:}

Wo often have $\{$ mist $\mid$ fog $\}$ along the coast.

\author{
CONNOTATIVE, DIM FNSIONS \\ Formal/informal: \\ He was $\{$ inebrialed $\mid$ drunk\}. \\ Abstract/concrete: \\ The $\{$ error $\mid$ blunder $\}$ cost him dearly. \\ Pejorative/favorable: \\ 'That suit makes you look \{skinny| \\ $\operatorname{sim}\}$.

\section{Forceful/weak:} \\ The building was completely \\ $\{$ destroyed $\mid$ ruined $\}$ by the bomb.
}

Table 1: Examples of features that dictionary usage notes adduce in word differentiation (adapted from [DiMarco and Hirst 1993]).

Relation comparison. The primary property is relation comparison: pairs of near-synonyms can be compared and judged as more, or less, similar to each other than others. For example, there is something similar in the relationship between stingy/frugal and between fat/plump. In each case, the first word (stingy, fal) is pejorative while the second (frugal, plump) has a nuance of being admirable or attractive. This relationship would not be maintained if, for example, we replaced fat/plump by rotund/plump.

Relation expressions. The second relation property is relation cxpressions, which refers to people's ability to use common words and phrases to express near-synonymic relations. For example, mistake and error both refer to something done incorrectly or improporly, but mistake is more general than error, according to the usage note in the $O A L D$.

Relation complexity. ${ }^{2}$ The property of relalion complexity refers to the need to represent different relations between the same pair of nearsynonyms, on more than one level of complexity; we need to be able to include nuances that are relevant to a given situation and ignore others.

Relation creativity. Chaflin and Mermanm observe that "the production and recognition of relations is a creative ability", so that the rolation between two words "can be readily identified although the reader may never have considered the relation of these particular terms before" [p. 292]. We will show that relation creativity is equally necessary to a theory of nearsynonymic relations. For example, the relation of

\footnotetext{
${ }^{2}$ Chaffin and Herrtaun [1988] use the sonewhat misleading term telation ambiguity, but we believe it is more accurate and less confusing to use the tern relation complexty.
}

arrange/organize ${ }^{3}$ can be recognized as one that contrasts correctness with functionality, and wo might then detect this same relationship for other pairs of near-synonyms (e.g., trim/shave).

In summing up the importance of these relation properties to a theory of semantic relations, Chaffin and Hermann state that "these diverse phenomena must be explained by theories of relations" and "we will find that in order to explain relations it is necessary to assume that relations are normally composed of more primitive elements that account for their characteristics and for people's abilities to make judgments about them" [p. 292]. We believe these observations are equally true of theories of plesionymic relations and we will show that a relation-element theory of near-synonymy will account for these relation properties.

\subsection{Theoretical assumptions}

In developing their theory of semantic relations, Chaflin and Herrmann make the following representational assumptions [paraphrased from pp. 293-294]:

- A relation $R$ between two concepts $x$ and $y$ is composed of a set of dyadic relation elements $\left(E_{a}, \ldots, E_{n}\right)$ :

$$
{ }_{x} R_{y} \longrightarrow\left(H_{a}, \ldots, H_{n}\right)^{4}
$$

- Relation elements may be hicrarchically organized so that, the presence of one element depends on the presence of another, or elements may be independent of one another. In the following representation, independent

\footnotetext{
3 "Arrange is to put in a pleasing or correct order ... Organize is to put into a working system" (from the usage note in the $O A L D$ ).

${ }^{4}$ This notation should be read as "the relation $R$ decomposes to the relation elements...".
} 
elements are separated by commas and de pendent elements appear in parentheses following the element that they depend on:

$$
{ }_{x} R_{y} \longrightarrow\left(b_{1}\left(l_{2}\left(H_{3}\right)\right), H_{1}^{\prime}, \ldots, F_{n}\right)
$$

- Relations may share one or more clements. The greater the proportion of elements two relations have in common, the more similar they are.

'Two examples of Challin and Ilermann's scmantic relations are synonymily and pseudoantonym, which they define in terms of the fol lowing sets of relation clements:"

synonymity: intersection (inclusion (bilateral)) pseudoantonym: dimension (bipolat, connotaiive)

We will adapt these representa tional assumptionst to our study of plesionymy and use them in constructing noar-synony mic relations from the relation elements to be defined bolow.

\section{The relation elements}

Chaflin and Herrmann define a set of relation elements of which semantic relations are composed. These relation eloments are described as "elo." ments that the relations had in common and eloments that distinguished the relations from each. other" [p. 301]. We observe that, for our purposes, a relation element is a denotational or connotative feature that is part (or all) of a descrip) dion of a near-synonymic relation; and hence nearsynonymic relations can be differentiated by these various elements. Thus, given this observation, we can consider our features of differentiation, as illustrated in 'lable $L$, to bo examples of the relation clements that compose, and distinguish, near-synonymic relations.

We stipulate that our near-synonymic rolation elements are anitary, that is, they represent lexical relationships that need not be decomposed any further. While we expect that relation $\mathrm{c}$ ements will be language-independent, the degree to which relation elements need to be decomposed might differ from langnage to language: we will refine the olement to exactly the level of distinction necessary for the plesionyms of the language, and no further.

\footnotetext{
${ }^{5}$ Note that Chaflin and Ilerrmamn tieat synonymy as a singke semantic: relation, while we are inberested in the nany diflerent near-synonymic relationships that can exist.

${ }^{6}$ I.ack of space precludes a full explanation of these relationclement structures, but it is not necessary for understaurling the: work we will present.

7 Chaffin and Ilerrmann also make processing assumplions, including one that relates to psychological verification of their relations; we do not use these assumptions in this paper.
}

\section{The relations}

We will work through several examples, showing how near-synonymic relations can be constructed from relation elements. All the word descriplions; in the examples bolow will be taken from usage notes in the $O A L D$. Our lirst example is the representation of the distinction between ask and be. seech:

[Ask] is the most usual and informal word ... beseech [is] stronger and more formal than beg.

Irom this usage note, and onr own native speaker knowledge, we identify the relation elements that distinguish each word:

ask: general; informal

besech: formal: forectul

This notation can be read as "ask is more gen. cral and more informal than beseech; beseech is inore formal and more rletorically fotceful than ask." We construct the relation between ask and besech by taking the complement of their respechive relation-element stuctures and then indicat. ing dependencies between the resulting relation olenents:

ask/besech: (general (formal ${ }_{\mathrm{ji}}$, forcelul $\left.\mathrm{ji}_{\mathrm{j}}\right)$ )

'This rolation states that ask is less formal and less forceful than beseech. (The ji subscript on formal and foreful should be read as indicating the direction of the relationship between word $j$ and word i.) 'This notation also shows that the relation elements formal and forceful are both dependent on the dominant element general.

Chaftiu and Hermann show that for seman tic relations, the same relation can hold betwen more than one pair of words. As this next exanmple for thin and emeciated shows, the same plesionymic relation (in this case, the relation between ask/besech) can hold between more than one pair of words. The $O A L D$ usage note for thin and emaciated describes them as follows:

Thin is the most general word. It may be negative, snggesting weakness or lack of health ... Emaciated indicales a serious condition resulting from statration.

Wo identify the relation elements that distingnish thin and cmacialed:

thin: general

emaciated: formal; forcelul

We take the complement of these relation clements and indicate the dependencies:

lhin/emacialed: (gencral (formal.ji, forceful ${ }_{\mathrm{ji}}$ ))

A more complex example is the rolation be twoen ruarel and row. The $O A L D$ usage note describes their distinguishing features as follows: 
$\Lambda$ quarrel is a sharp, often angry, exchange of words between people ... A row is angry and may involve shouting, usually for a short time ... A row can also take place between public figures or organizations.

There are two ways we can construct the relation between quarrel and row, depending on whether the argument is between people or inanimate organizations:

quarrel/row:

(forceful, formal ${ }_{\mathrm{ji}}$, emotional $\mathrm{j}_{\mathrm{ji}}\left(\right.$ vectorial $\left._{\mathrm{ji}}\right)$ ) quarrel/row:

(forceful, inanimate ${ }_{\mathrm{ji}}\left(\right.$ formal $\left._{\mathrm{ji}}\right)$ )

The first relation states that row is more formal and more emotional; quarrel is more forceful. It also indicates that the greater emotion of a row is linked to a difference in scale, the vectorial element, which in this case refers to the different lengths of time of a quarrel and a row. The second relation notes that a row can involve inanimate entities but, if it does, then the effect is more formal. Thus, we can have different relations between plesionyms, depending on the different usages of the words.

By following the same kind of approach, we can construct relations for some other pairs of nearsynonyms:

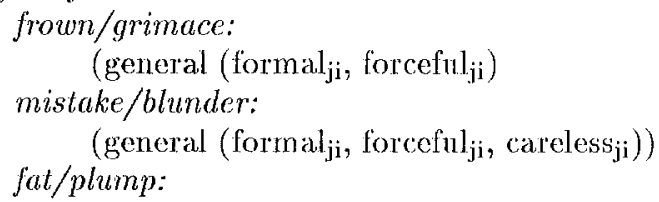

We observe that the same or similar relation can hold between different pair's of near-synonyms, for cxample, ask/besecch, thin/cmaciated, and frown/grimace. This is analogous to the case of semantic rolations, which, as Chaffin and Herrmann note, are readily recognizable and nameable. Near-synonymic relations cannot be so easily labelled, but we can still see that some basic set of relations might be defined and could be used to construct new relations. Fír example, we showed that the relation between ask and beseech could be represented by the following structure:

ask/beseech:

(general (formal ${ }_{\mathrm{ji}}$, forccli $\left._{\mathrm{ji}}\right)$ )

We saw how this basic relation could also apply to thin/emaciated and frown/grimace; this sug. gests that, for lexical-choice processing, we will want to keep a catalogue of existing relations from. which new relations could be built. Another pair of near-synonyms, mistake and blunder, share the same distinctions, except that blunder is often the result of carelessness ( $O A L D$ ). So we add to the existing specification to obtain the following relalion:

$$
\text { mistake/blunder: }
$$

(general (formal ${ }_{\mathrm{ji}}$, forceful ${ }_{\mathrm{ji}}$, careless $\left.\mathrm{ji}_{\mathrm{ji}}\right)$ )

Lastly, dependencies can load to quite complicated relations, as in the case of fat/plump, where the distinction of politeness (impoliteness) is related to different dependencies for each nearsynonym: the nuances of force and impoliteness are interdependent, as are those of politeness and attractiveness.

\section{$6 \quad$ The relation properties}

In Section 3.1, we set out a list of relation properties that any theory of near-synonymic relations should be able to account for. In this section, we discuss how a relation-element approach addresses these issues.

Relation comparison. By breaking down the relations betwoen plesionyms into relation elements, we can obtain a finer degree of discrimination betwoen similar words for the task of lexical choice in generation. As we discuss in [DiMarco, Hirst, and Stede 1993], many of the semantic distinctions between plesionyms do not lend themselves to neat, taxonomic differentiation; rather, they are fuzzy, with plesionyms often having an area of overlap. For example, the boundary between forest and wood is vague, and there are some situations in which either word might be equally appropriate. The problem is compounded when we are dealing with more than one language, for the 'breakpoint' between small and large tracts of trees is different for different langnages. For multilingual generation, we can compare plesionyms in different languages in terms of their different clement structures, so that it should be easier to choose the particular word in a particular language that fits a given situation.

Relation expressions. We have seen that often the distinctions betwoen near-synonyms noed to be expressed using common words and phrases. But we have shown that there are ways of expressing relations using fairly common vocabu. lary to represent those distinctions. The case of relation identilication may contribute towards relation verification: we can anticipate that psychological tests, of the sort Chaffin and Herrmann carried out for semantic relations, could be used to verify our relations and relation elements, as we can meaningfully and precisely represent the subjects' intuitions about the distinctions between near-synonyms. 
Relation complexity. Relations may need to be described at more than onc level of complexity, so that the distinctions between two words may be identified in more than one way. We have shown how a relation-element approach allows us to define different relation structures for the satne pair of near synonyms (e.g., quarrel/row).

Relation creativity. Wo have noted in previous work [DiMarco, Mirst, and Stede 1993] that the representation of the distinctions between near-synonyms would seem to require a constrained, but not finite, vocabulary. With a relation-element approach, we have seen how a basic set; of relations might be consitructed; new relation elements may bo added, but we may be able to incorporate them into existing relations, so that the catalogue of relations need not grow uncontrollably. 'J'hus, we cau produce new relations by elaborating on existing, well-known relations or by concatenating existing relations [p. 322].

\section{Implementing near-synonymic relations}

We are currently investigating different systems for implementing a relational theory of neassynonymy. 'The first system that we are looking at is WordNet [Miller et al 1990], which secms particularly relevant as words aro organized both by semantic relations and by "synsels" (synonym sets).

WordNet contains definitions of nouns, verbs, and adjectives; for now, we aro concentrating on the representation of adjectival noarsynonyms. In kepping with the philosophy of WordNet, we envisage the use of a pointer for each type of near-synonymic relation in our catalogue, so that wo might represent the relations between plesionyms as follows: r1 : (general ( favourable $\left.\mathrm{c}_{\mathrm{j} j}\right)$ )

$\mathrm{r} 2$ : (general (formal ${ }_{\mathrm{ji}}$, for ceful $\left.\mathrm{ji}_{\mathrm{ji}}\right)$ )

r3: (general (favourable, forcef $\left.{ }^{1} l_{j i}\right)$ )

Currentity, the coding of a synset of adjectives would look as follows in WordNet:

\{thin, slender, emaciated, thin $1, \&\}$

where "thin l, \&" indicates that members of this synset are related to the 'concepl' thint by the similarity relation.

We cas imagine imposing additional struchure on a synset and making use of a catalogue of nearsynonymic relations to obtain the following coding:

\{ [thin, slender, r1], [thin, emaciated, r2], [stender, emaciated, r3], thin $1, \&\}^{8}$

\footnotetext{
${ }^{8}$ In WordNet, square brackets are used to indicate a lexical
}

While such a representation of near-synonymic relations would be very easy and natual in Word. Net, it relies on the solution of a number of chal-. lenging problems, specilically, how to generate a complete set of near-synonymic relation elements, and how to define a constrained and reusable cat alogue of near-synonymic relations.

\section{Conclusion}

Our eventual goal is a knowledge representation for the discrimination of near-synonyms. We have taken a step towards such a representation by investigating the nature of neas-synonymic relations. We have set out four properties that any theory of near'synonymic relations shond ad.dress, and we have shown how relation-clement theory gives us a way of representing distinctions between near-synonyms that accounts for these properties. We are currently investigating the representation of our relational approach to nearsynonymy in the Word Net system.

\section{Acknowledgements}

We thank Gracme llirst for reading and giving incisives comments on carlier drafts of the paper. We also thank the anonymons referees for suggesting an extentsion of this work. We acknowledge the support of the Natural Sciences and Eingineering Reseatch ('ouncil of Canada.

\section{Referencess}

DiMarco, Chrysanno and Hinst, (Graeme. "Usage notes as the basis for a representation of near-synonymy for lexical choice." lrocedings, Ninth Annual Conference of the University of Waterloo Centre for the New Oxford Finglish Dictionary and 'lext Research, Oxford, Septenter 1993, 33-43.

DiMarco, Chrysanne; Hirst, Graeme; and Stecle, Manfred. "The semantic and stylistic differentiation of synonyms" and near-synonyms." l'rocedings, AAAI Spring Symposium on Building lexicons for Machine Thanslation, Sitinford, March 1993.

Chaffin, Roger and Hermann, Donglas J, "lhe nature of semantic relations: $\Lambda$ comparison of two approaches." In: Retutional modcls of the lexicon, Martha W. livens (colitor), Cambridge Universily l'ress, 1988, 288334.

Cruse, D.A. Lexical semantics. Cumbridge University P'ress, 1986.

Miller, George A.; Beckwith, Richard; Fellbaum, Christiane; Ciross, Derek; and Milles, Katherine. "l"ive papers on Wordnet." CSL Report 43, July 1990, Cognitive Science laboratery, Princeton University.

Oxford sdvanced learner's dictionary of curvent linglish, fourth edition. Oxford Viniversity Press, 1989.

Vinay, J.P. and Darbclnet, I. Stylistique comparée du français et de l'anglais. Beauchemin ltće, 1958.

relation between words, rather than a semantic relation between concepts. 